\title{
Effects of Restricting Water to Growing, Lactating and Pregnant Buffaloes Reared in a Hot and Humid Environment
}

\author{
N. TILAKARATNE AND S. S. E. RANAWANA \\ Veterinary Research Institute, Peradeniya, Sri Lanka \\ AND
}

\section{A. SRIKANDAKUMAR}

Faculty of Veterinary Medicine and Animal Science, University of Peradeniya, Peradeniya, Sri Lanka.

(Date of receipt: 06 September 1982)

(Date of acceptance: 09 February 1983)

\begin{abstract}
An experiment was carried out to examine the effects on certain physiological indices of heat stress in buffaloes subjected to restriction of water in a hot (Air temperature = $27.6-32.8^{\circ} \mathrm{C}$ ) and humid (Relative humidity $=62-84 \%$ ) environment. Five each of growing (Mean age $=10$ months), lactating (Mean milk yield $=5$ litres $/$ day) and pregnant $(8-9$ th month of gestation) Surti buffaloes were grazed under young coconut palms and subjected to three treatments in successive periods, each of three week duration. Each treatment was imposed on all groups of animals simultaneously. In treatment I referred to as the normal management, animals were allowed drinking water ad libitum and wallowed for 1.5 hours daily. In treatment II wallowing was denied, and treatment III comprised restriction of drinking water in addition to denial of wallowing. Thermal stress was monitored by measuring rectal and skin temperature, respiration, pulse and cutaneous evaporation sates of each animal several times a day
\end{abstract}

All physiological variables studied showed a progressive increase from 0700 hours till 1400 hours and declined towards 1800 hours. The time effect was very highly significant $(P<0.001)$. Under normal management, growing heifers were found to be more stressed than the adults. Denial of wallowing and restriction of drinking water caused an aggravation of heat stress with an average elevation of $0.9-1.2^{\circ} \mathrm{C}$ in rectal temperature and $16-18$ respirations per minute at mid day over their respective base values. No significant group difference was observed during the latter treatments. The average rate of cutancous evaporation of $310 \pm 15$ during treatment I decreased to $271 \pm 15 \mathrm{~g} / \mathrm{m}^{2} /$ hour in treatments II and III. Heifers generally showed a lower rate of cutaneous evaporation and higher rate of respiration

The results indicate that despite shade the buffaloes suffered from heat stress as the ambient temperatures increased. Lack of wallowing and restriction of drinking water aggravated the stress. Young animals were possibly more dependent on the pulmonary route for evaporative cooling. Adult buffaloes did show a capacity to lose moisture through the skin at rates comparable to those of zebu cattle.

\section{Introduction}

Buffaloes in general, show a greater affinity to water than other domestic ruminants. It is believed that the habit of wallowing in water or in wet mud plays a crucial role in the dissipation of excess body heat, while drinking water is also known to play somewhat a 
lesser role in thermal regulation. Tropical regions frequently encounter periods of drought when supply of adequate water becomes a problem. The combined effects of hot and humid environments of the tropics and scarcity of water may act as a limiting factor to the survival and productivity of buffaloes maintained in such environments. In view of the envisaged plans to utilise buffalo as a major source of milk and draught power in Sri Lanka, a complete understanding of the interactions of the buffalo with the tropical environment should prove useful. The present study was undertaker to study the effects of restricting water, both for wallowing and drinking, under hot-humid conditions to growing, pregnant and lactating buffaloes of a recognised dairy breed.

\section{Materials and Methods}

Animals used in the experiment were chosen from the herd of Surti buffaloes on the National Livestock Development Board Farm at Melsiripura. They comprised five each of growing heifers (average age $=10$ months, weight $=140 \mathrm{~kg}$ ), pregnant (mean age $=8$ years, weight $=387 \mathrm{~kg}$ and in 8 th to 9 th month of gestation) and 'actating (mean age $=8$ years, weight $=344 \mathrm{~kg}$ and yielding 5 litres of milk per day) cows.

Animals were grazed continuously on cultivated pasture - Brachiaria miliformis under young coconut trees which intercepted approximately $70 \%$ of the solar radiation. They were also supplemented with cut grass in the night. Lactating animals only were provided with supplementary concentrate feed. Milking was donc twice daily at approximately 12 hour intervals. Except when required as a part of the experimental treatment animals had continuous access to drinking water provided in-a trough and were also wallowed in a lake between 1430 and 1600 hours each day.

Animals were subjected to the following three treatments, each treatment imposed on all 3 groups simultaneously.

Treatment I:-

All animals were managed as described above; they were allowed drinking water al libitim and wallowed for 1.5 hours daily.

Treatment II:-

Same as above but they were not allowed to wallow.

Treatment III:-

Animals were not allowed to wallow. In addition water for drinking was restricted by offering only every other day.

Each of the treatments I and II lasted three weeks while the duration of treatment III was 4 weeks. Measurements were made during the last two weeks allowing one week for adjustment for Treatments I and II and 2 weeks of adjustmeat in the case of Treatment III.

The following measurements were made on each animal in each treatment at $700,900,1200,1400$ and 1800 hours. Rectal temperatures were measured by means of a. clinical thermometer and respiration rates by counting flank movements. Skin 
temperature was measured on the belly about $7 \mathrm{~cm}$ lateral to the mid line using an electric thermometer with a touch thermocouple. Cutaneous evaporation rate was ascertained from a clipped patch on the dorsal lumbar region by using cobalt. chloride impregnated paper discs according to Schleger and Turner. ${ }^{13}$ On standardising the technique it was found that $11.2 \mathrm{~g}$ water $/ \mathrm{m}^{2}$ paper were required to change the colour of the disc from violet to bright rose.

Respiration rates were measured before disturbing the animals. Thereafter, each animal was tied to a coconut tree and the balance measurements were made, the rectal temperature being taken last. Within a few days, the animals settled down to the procedure and showed no signs of excitement.

\section{Analysis of data}

Separate analyses were performed within each treatment-period to ascertain the effects of time of observation within treatment.

Data from each time of observation were subjected to analysis as a split plot in accordance with Gill and Hafs ${ }^{5}$ for repeated measurements on the same animal. The model used in this instance included the effects of groups of animals, treatment and group $x$ treatment interaction. Group and treatment means in each case were compared according to Duncan's multiple range test.

\section{Results}

The ambient temperature and humidity levels that prevailed at the location of the experiment during the study period are presented in Table I. It will be seen that the climatic conditions were not subjected to much variation across 3 treatment periods. The Group - Treatment - . Time of day sub class means of the different physiological variables are given in Tables 2 and 3. In all treatments rectal and skin temperatures, respiration, pulse and cutaneous evaporation rates showed a progressive increase up to 1400 hours and showed a decline at 1800 hours (Figures 1 a to $1 \mathrm{e}$ ). The time effect was significant $(P<0.001)$ on all variables (Table 4 ). Although the measurements relate to fixed times of the day, in effect they could be related to variation in environmental temperature and humidity. It is in terms of the latter that the results will be discussed

\subsection{Rectal temperature}

Rectal temperature of growing heifers was found to be generally higher than that of adult cows: In Treatment 1 , heifers also recorded a significantly greater elevation of rectal temperature. There was no significant treatment effect on the base values of the groups. With the restriction of water, although the heifers continued to record higher temperatures at any given time the elevation at higher air tenperature was less $(0.8 \% \mathrm{c})$ than those of pregnant and lactating cows $(1.2 \% \mathrm{C})$. 


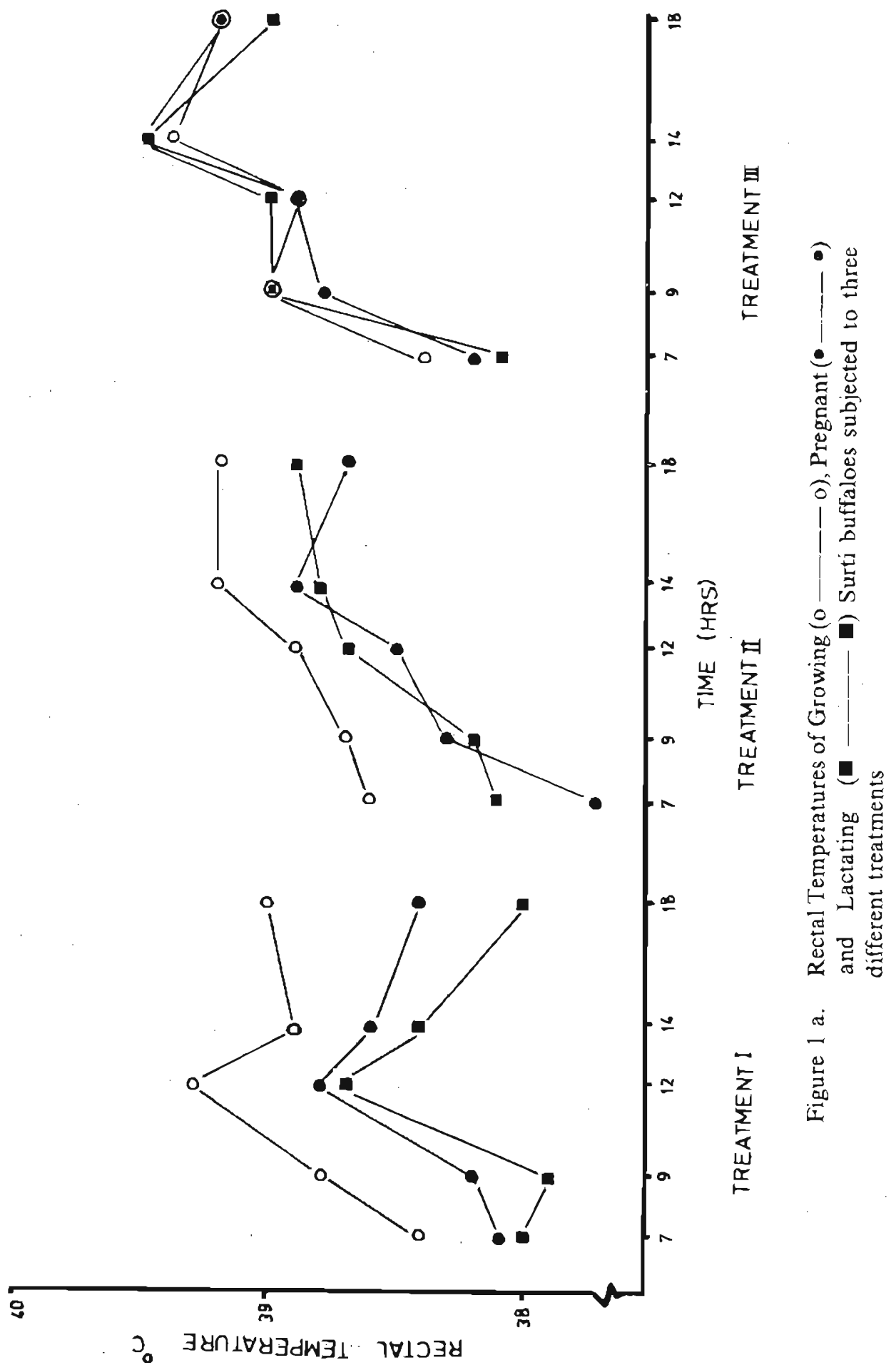



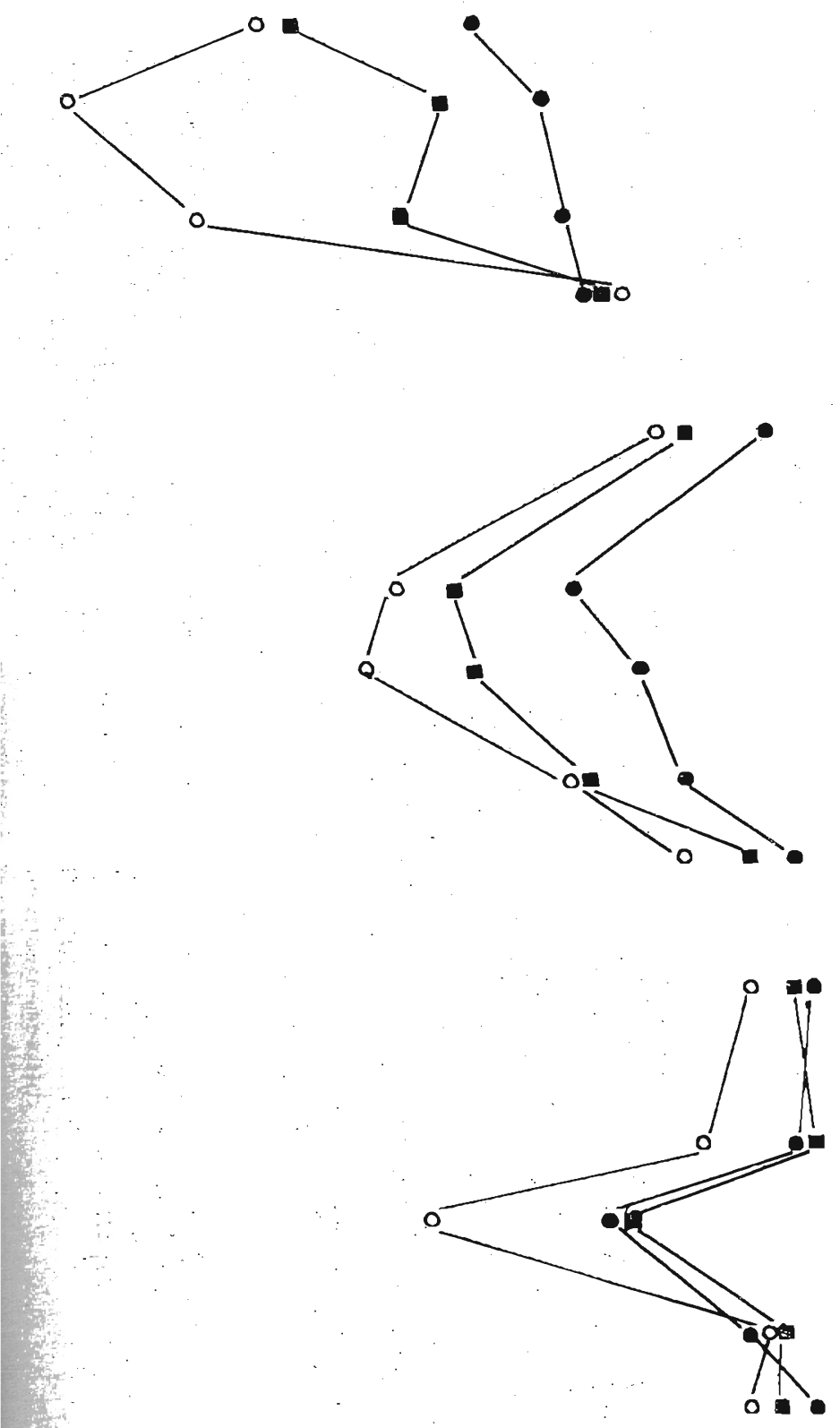

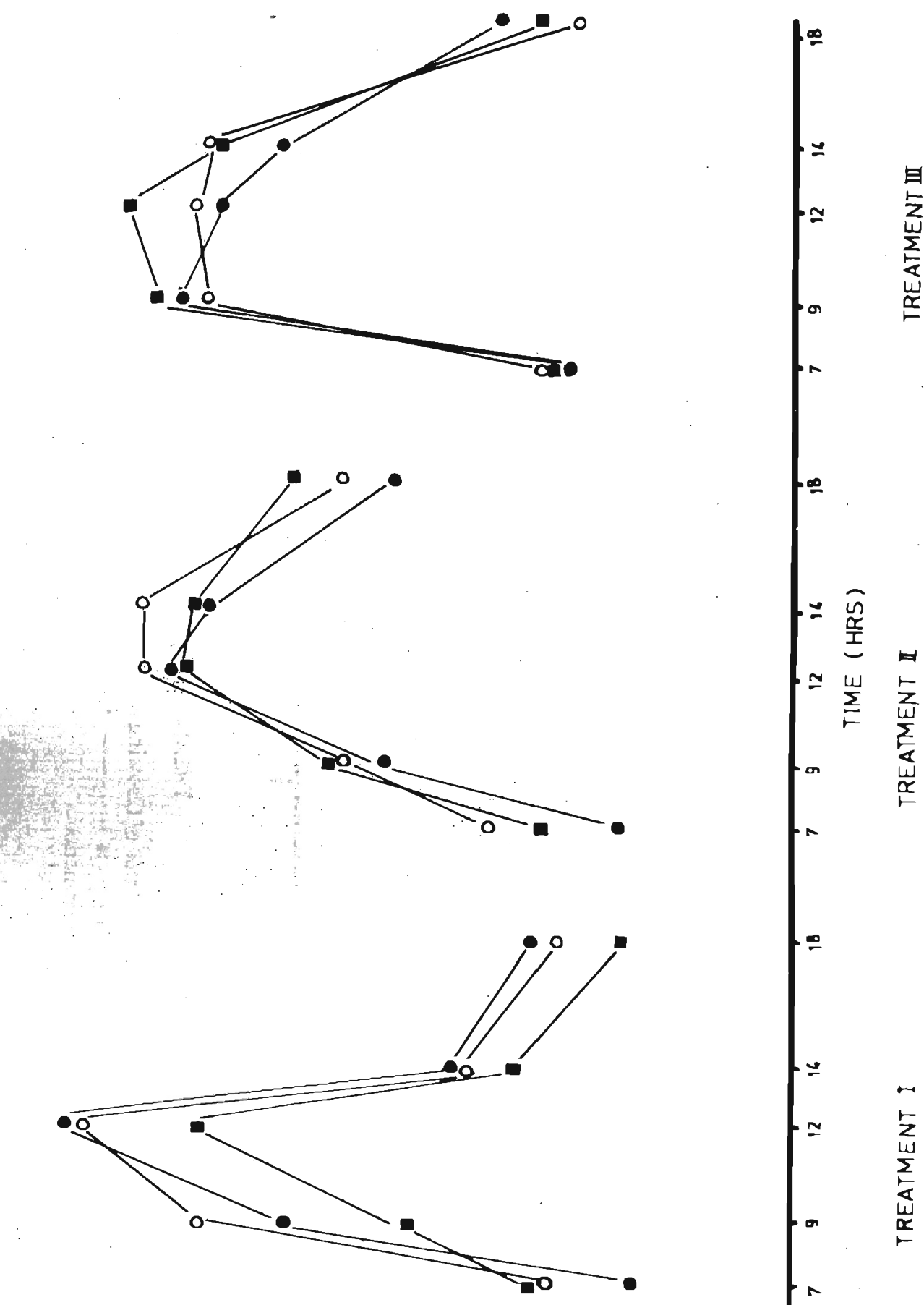

1

$\frac{\hat{n}}{\frac{\underline{r}}{\Sigma}}$

$\frac{\text { 目 }}{2}$

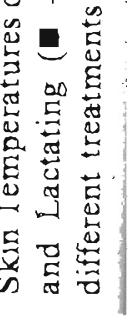

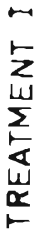
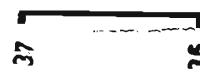

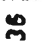

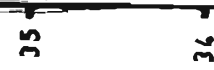

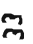

กุา

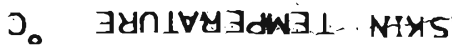



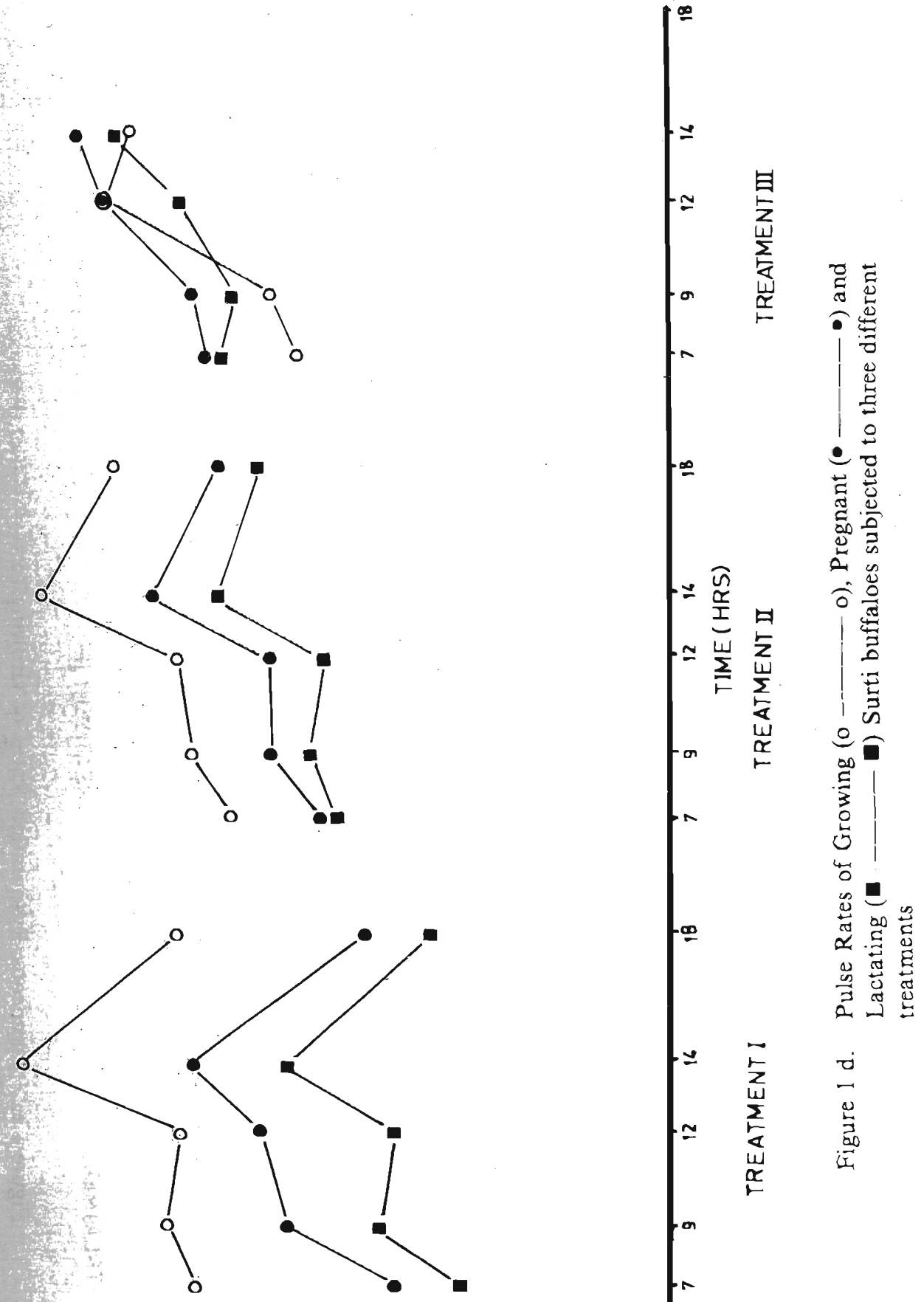

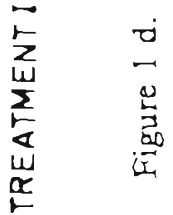



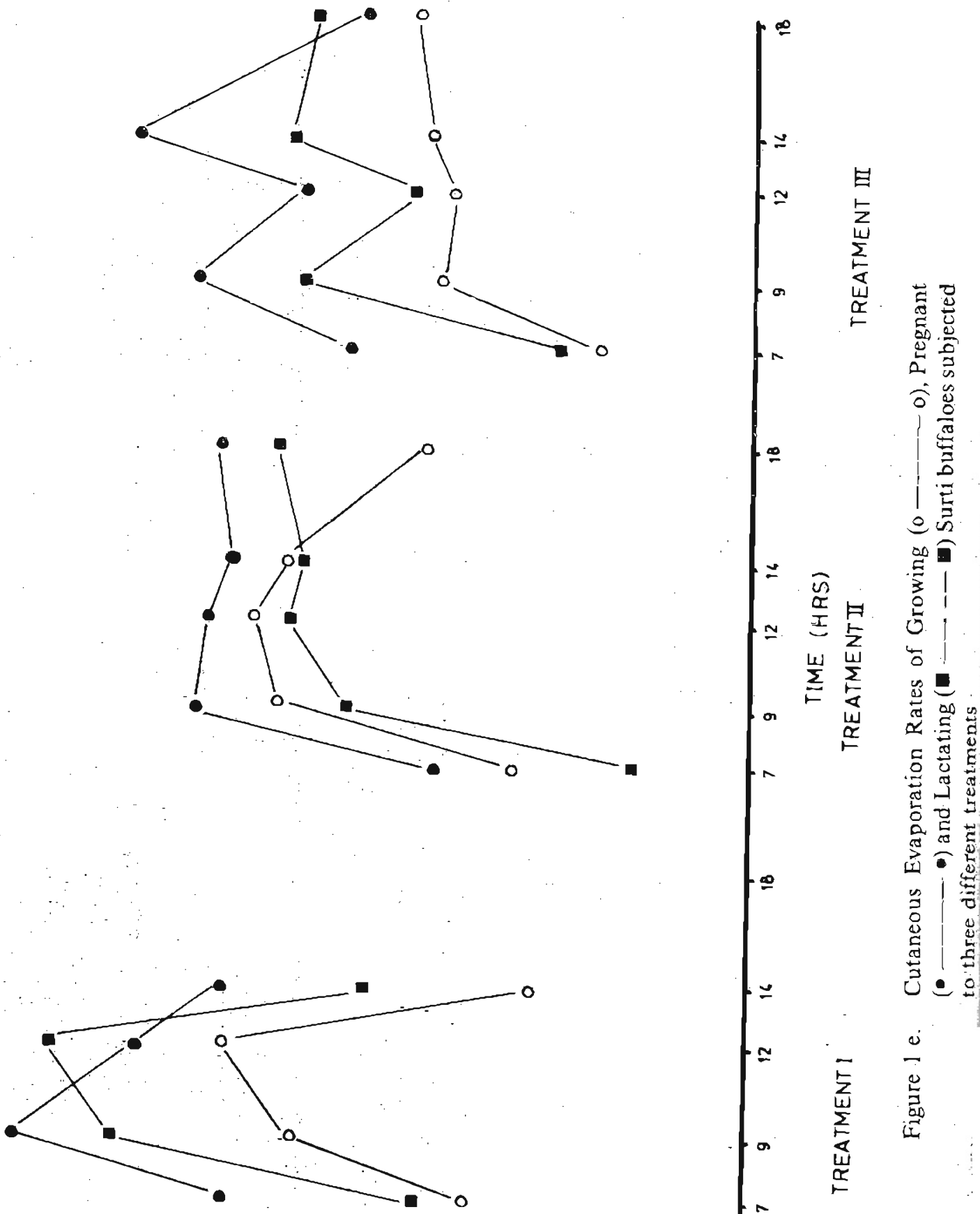


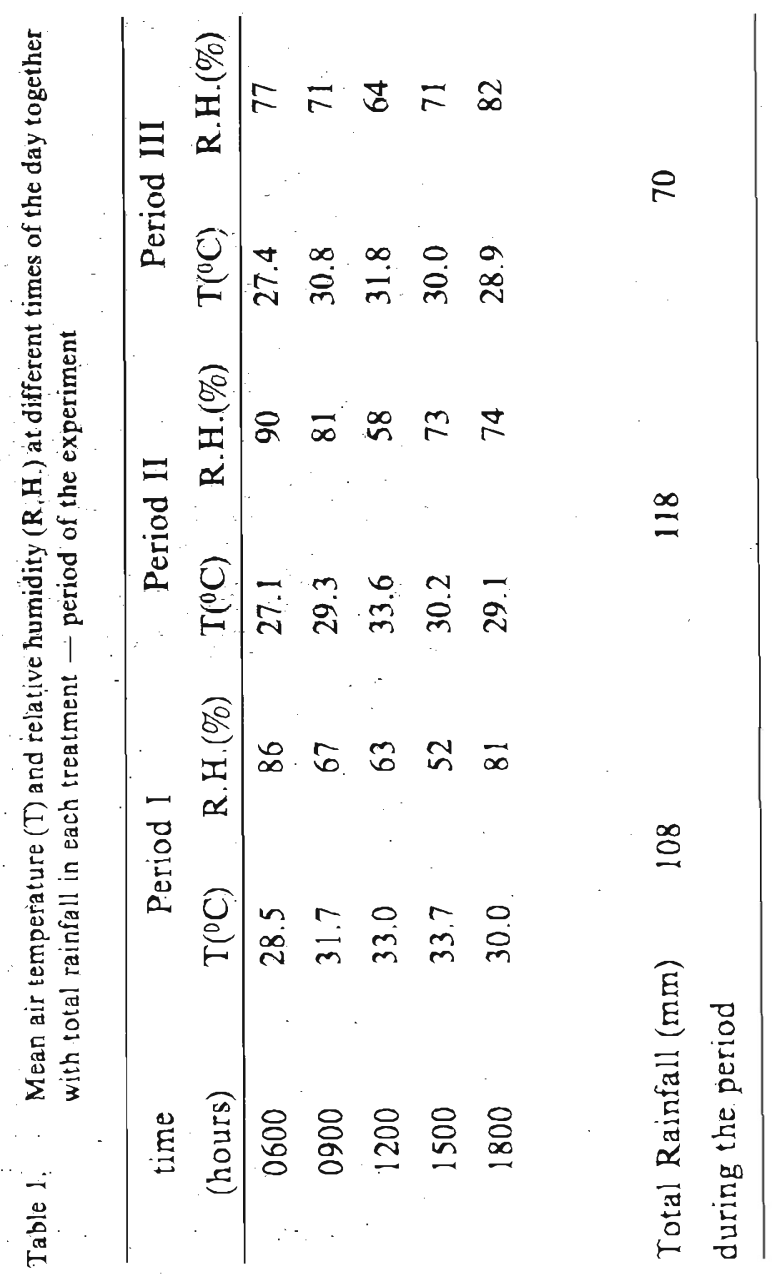




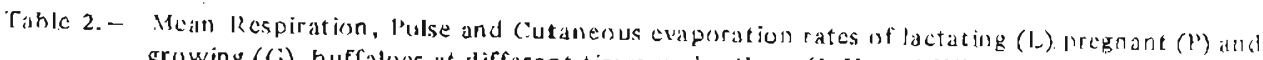
growing ( (i) huffalacs at different times under three (I, Il, and III) trealloments.

\begin{tabular}{|c|c|c|c|c|c|c|c|c|c|c|}
\hline \multirow[t]{2}{*}{$\begin{array}{l}\text { Time of } \\
\text { day }\end{array}$} & \multirow{2}{*}{$\begin{array}{l}\text { Group } \\
\text { of } \\
\text { animals }\end{array}$} & \multicolumn{3}{|c|}{ Respiration/Min } & \multicolumn{3}{|c|}{ Pulse/Min } & \multicolumn{3}{|c|}{$\begin{array}{l}\text { Cutaneous } \\
\text { evaporation } \mathrm{g} / \mathrm{m}^{2} / \mathrm{hr}\end{array}$} \\
\hline & & I & II & III & I & II & III & I & II & III \\
\hline \multirow[t]{3}{*}{0700} & $\mathbf{L}$ & 21.4 & 22.6 & 31.6 & $46.4^{\pi}$ & $55.0^{x}$ & 63.8 & $234^{x}$ & 148 & $182^{x}$ \\
\hline & $\mathbf{P}$ & 19.4 & 20.0 & 32.8 & $50.6^{x}$ & $56.2^{x y}$ & 65.2 & $315^{y}$ & 228 & $266^{y}$ \\
\hline & $G$ & 22.6 & 26.8 & 31.8 & $66.2^{y}$ & $63.4^{y}$ & 58.0 & $214^{x}$ & 200 & $164^{x}$ \\
\hline \multirow[t]{3}{*}{0900} & $\mathbf{L}$ & 21.4 & 33.4 & 44.4 & $52.0^{x}$ & 57.0 & 63.2 & 361 & 265 & $286^{x y}$ \\
\hline & $P$ & 22.6 & 27.4 & 34.4 & $59.2^{x y}$ & 59.8 & 65.8 & 402 & 332 & $330^{x}$ \\
\hline & G & 22.1 & 34.2 & 57.8 & $67.6^{\dot{y}}$ & 65.8 & 59.6 & 284 & 295 & $228^{y}$ \\
\hline \multirow[t]{3}{*}{1200} & $\mathrm{~L}$ & 30.8 & $39.6^{x y}$ & $42.2^{x}$ & $51.4^{x}$ & $56.4^{x}$ & 67.4 & $385^{x}$ & 290 & 240 \\
\hline & $\mathrm{P}$ & 32.0 & $30.4^{x}$ & $35.8^{x}$ & $61.0^{y}$ & $59.6^{x y}$ & 73.4 & $350^{x y}$ & 327 & 285 \\
\hline & G & 43.0 & $47.2^{y}$ & $66.2^{y}$ & $67.2^{y}$ & $67.2^{y}$ & 73.0 & $315^{y}$ & 305 & 225 \\
\hline \multirow[t]{3}{*}{1400} & $\mathrm{~L}$ & 19.4 & 40.8 & $51.6^{y}$ & $58.8^{x}$ & $64.4^{x}$ & 72.0 & $257^{x y}$ & 286 & $290^{x y}$ \\
\hline & $P$ & 20.2 & 34.0 & $40.2^{x}$ & $65.6^{x}$ & $68.6^{x}$ & 75.4 & $315^{x}$ & 315 & $355^{x}$ \\
\hline & $G$ & 26.2 & 45.0 & $54.0^{y}$ & $80.2^{y}$ & $77.6^{y}$ & 71.0 & $192^{y}$ & 287 & $235^{y}$ \\
\hline \multirow[t]{3}{*}{1800} & L & 19.4 & $27.0^{x y}$ & NR & $47.8^{\times}$ & $61.0^{x}$ & NR & NR & $295^{x}$ & 281 \\
\hline & $\mathrm{P}$ & 19.0 & $22.4^{x}$ & NR & $53.4^{x}$ & $64.4^{x y}$ & NR & NR & $320^{x}$ & .260 \\
\hline & $G$ & 22.5 & $28.6^{y}$ & NR & $67.3^{y}$ & $72.4^{y}$ & NR & $N R$ & $235^{y}$ & 242 \\
\hline \multicolumn{2}{|c|}{$\begin{array}{l}\text { Pooled s.e. } \\
\text { of mean }\end{array}$} & \multicolumn{3}{|c|}{3.6} & & \multicolumn{2}{|l|}{2.9} & \multicolumn{3}{|c|}{15} \\
\hline
\end{tabular}

Figures with different superscripts within treatment - lime sub class are significantly
differeni $(P<0.05)$ 
Table 3. Mean rectal and skin temperatures of lactating (L), Pregnant (P) and Growing ( $(3)$ buffaloes at different times under three (I, II and III) trcatments.

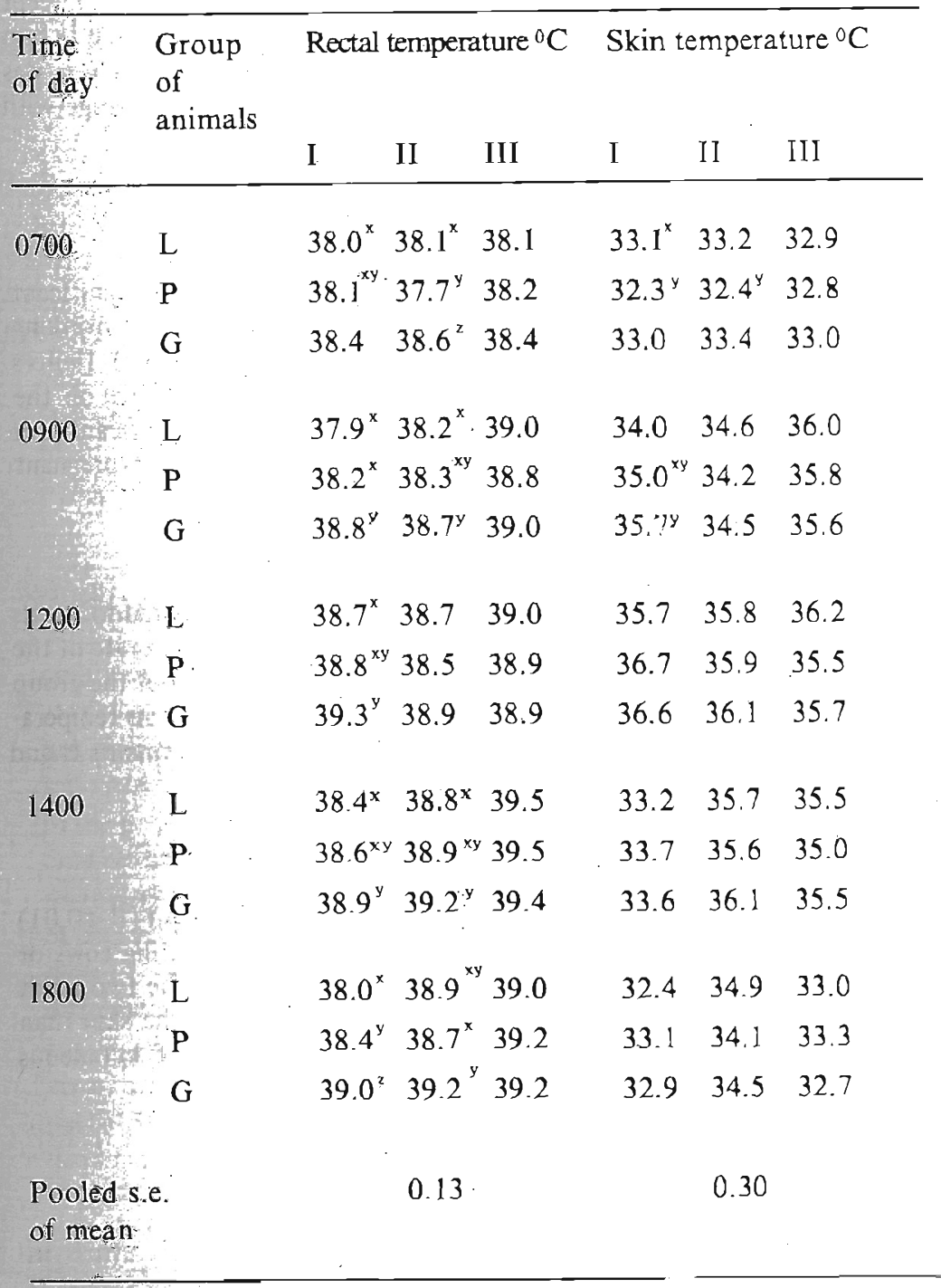

Figures with different superscripts within treatment - time sub class are significantly different $(P<005)$ 


\subsection{Skin Temperature}

The mean basal skin temperature across groups and treatments was $30.0 \pm 0.3 \% \mathrm{C}$. Except for a significantly lower temperature of the pregnant animals in treatments I and II skin temperature did not differ among groups or treatments at any of the times. There was also a significant group $\mathrm{x}$ time interaction showing that the magnitude of change with time was not uniform across groups.

\subsection{Respiration}

In Treatment I and II the basal respiration rate averaged $22 /$ minute with no significant differences among groups. Denial of wallowing together with deprivation of drinking water caused the basal respiration rate to increase significantly (Mean $=32 / \mathrm{min}$ ). Heifers had higher rates at higher temperatures. Treatments had no significant effect on the elevation of respiration rates at higher air temperatures. Groups differed significantly in the rise of respiration rates in Treatment III in the order heifers $>$ lactating $>$ pregnant
cows.

\subsection{Pulse}

A significantly higher pulse rate was observed in heifers (Mean $=65.3$ ) compared to adults (Mean $=52.0$ ) in treatments I and II only. A significant rise in the basal pulse rate of the adults, indicating a group $\mathrm{x}$ treatment interaction, resulted in the elimination of the group differences in treatment III. Heifers also showed a greater elevation at higher air tempera. tures. This difference in elevation was significant only at 1400 hours in treatments II and III.

\subsection{Cutaneous evaporation}

Base values of cutaneous evaporation in treatment I and II showed a significant $(P<0.01)$ group difference with pregnant cows having a higher rate than either lactating cows or the growing heifers. However, at higher air temperatures it was seen that the two adult groups lost significantly $(\mathrm{P}<0.01)$ greater amounts of moisture through the skin than the heifers. Restriction of water caused a general decline in the rates of cutaneous evaporation in all three groups.

\section{Discussion}

Shade is considered to be an important factor in ameliorating climatic stress in buffaloes. However, as reflected by rectal temperature and respiratory responses it was evident that the animals in this study, despite some protection from direct sunlight, were subjected to thermal stress as the environment became warmer.

Evaporation of water through pulmonary and cutaneous routes is known to play a significant role in heat loss ${ }^{3}$ in mammals, while Pandey and Roy ${ }^{12}$ considered respiratory evaporation to be of greater importance than other mechanisms in 
maintaining héat balance in buffaloes. The observed changes in the different physiological parameters in association with changes in air temperature and humidity are therefore to be expected, and agree with those reported for cattle and buffaloes 8,9 exposed to sun at comparable air temperatures.

Trends in rectal temperature and respiration rates in the heifers under normal management (Treatment I) would indicate that they were less efficient in overcoming heat stress. Pal ${ }^{11}$ and Asker, Ragab and Ghany ${ }^{2}$ have concluded that buffalo calves suffer much more from heat than adults do. However, it has been shown that the increase in heat tolerance of adults is interrupted by lactation and pregnancy. 1,2 Enhanced heat production due to increased metabolism in the latter categories of animals make them more vulnerable to heat stress. Our results, therefore are at variance from expectations. Conditions in treatment I probably had only mild effects for it was seen that the trend reversed in treatments II and III resulting in the adults being equally or much more stressed than heifers.

It is believed that buffaloes have a poor capacity to sweat due to a relative paucity of sweat glands. Hafez, Badreldin and Shafe ${ }^{6}$ calculated the area of glandular surface per unit area of skin to be only a third of that in cattie. Nevertheless, rates of cutaneous evaporation in Murrah buffaloes almost similar to certain breeds of zebu cattle have been observed at air temperatures of $40^{\circ} \mathrm{C}$ ' The rates recorded in our study are similar to those of the above study but higher than those of swamp buffaloes reported by Moran: ${ }^{10}$ In this context it is also noteworthy that the site of measurement in the present study - the dorsal lumbar region is noted to be the area with the lowest density of sweat glands in the buffalo ${ }^{6}$ whereas Moran ${ }^{10}$ measured in the shoulder region which has a much greater density. Furthermore our observation of a lower rate of moistuire loss in the heifers is in contrast with the reports that the sweat gland density, and therefore the sweating capacity in buffalo decrease with age. ${ }^{9}$ Genetic differences of the animals used, differences in site of measurement and in environmental conditions are likely factors responsible for the inconsistencies. However, it is also possible that all of the moisture was not due to true sweating but partly due to insensible loss of moisture by diffusion through the epidermis. Latter has been recognised to contribute significantly to moisture loss in a variety of animals. ${ }^{4}$ The decline in cutaneous evaporation associated with restriction of water may also support this explanation. Buffalo calves have a relatively more hairy coat. It is possible that diffusion of moisture is therefore, interfered with to some extent unlike in the adults, and the pulmonary route assumes greater importance in evaporative cooling in the heifers. This may explain the lower rate of cutaneous evaporation and higher respiration rates in the heifers.

It was readily apparent that denial of wallowing caused the lactating and pregnant animals to be more stressed whereas heifers were affected to a lesser extent. 
Data on water: metabolism showed that there was a dramatic increase in water turnover rates during this period (Ranawana, Tilakaratne, Srikandakumar, unpublished data). This was probably due to increased water intake as an attempt to compensate for the lack of wallowing. Apparently it did not help the animals to a notable degree. Thus the results underline the importance of wallowing to the buffalo as a means of cooling themselves.

In treatment III, when drinking water was restricted along with decline of wallowing it was seen that the heat tolerance was further affected and thermal stress aggravated, no doubt part of it was die to carry over effect from Treatment II. It must also be borne in mind that there is some confounding of treatment effects with the physiological status of particularly the lactating and pregnant cows. The advancing foetus of the pregnant animals would be expected to cause additional heat load while the milk yield of lactating cows was likely to decline with advancing stages of lactation resulting in a lesser heat load. In fact a progressive drop in average milk yield was observed (Period I $=5.24, \mathrm{II}=3.68$ and III $=2.39 \mathrm{~L} /$ day) with the treatment differences being significant $(P<0.01$ ). This decline, however, was evidently brought about by treatment effect since it was noted that the milk yield began to increase a week after the termination of the trial. The effects on milk yield were probably due to reduced feed intake as a result of thermal stress.

Surti is a breed of buffaloes developed in the North Western regions of India where the climate is extreme in both winter and summer. The present results however would indicate that this breed is not well adapted to an environment of high air temperature and humidity. This aspect needs to be considered in the choice of breeds of buffaloes for rearing under such conditions. Climatic stress was aggravated by denial of wallowing and restriction of drinking water which underlines the need for provision of facilities for wallowing or any other means of wetting. Another notable finding of the present study is that in contrast to the accepted concept, buffaloes do lose a significant amount of moisture through the skin. This capacity is relatively less in young animals in whom pulmonary evaporation seems to be more important.

\section{Acknowledgements}

The cooperation extended by Mr. G. Perera and Dr. V. Thamotheram and the rest of the management of the National Livestock Development Board Farm, Melsiripura is gratefully acknowledged. The authors also appreciate the technical assistance of Messis. D. M. Paranagama and S. M. T. Banda.

The study was supported in part by the International Atomic Energy Agency by award of a Research Contract (No. 2349). We are also grateful to Dr. John Vercoe, formerly of the Agency, for his help in the planning of the study. 


\section{References}

1. ALIM, K. A., AHMED, I. A. (1957). Studies on the body temperature and respiration rate of buffalo cows under normal conditions. Canadian Journal of Animal Sciences 37: $130-135$.

2. ASKER, A. A.; RAGAB, M. T. \& GHANY, M. A. (1953). Same factors affecting heat rolerance of cattle and buffaloes. Nature London 170: 457 - 458.

3. BLAXTER, K. L. (1966). The Energy Metabolism of Ruminants. London: Hutchinson Scientific and Technical. DUKES, H. H. (1957). The Physiology of Domestic Animals: p. 429. New York, Comstock Inc.

GILL, J. L. \& HAFS, H. D. (1971)_Analysis of repeated measurements of animals.Journal of Animal Science 33: $331-336$

HAFEZ, E. S. E.,BADRELDIN, A. L. \& SHAFEI; M. M. (1955). Skin structure of Egyptian buffaloes and cattle with particular reference to sweat glands. Journal of Agricultural Science, Cambridge 46: $19-29$.

JOSHI, B. C., McDOWELL, R. E. \& SADHU, D. P. (1968). Body surface evaporation rotes at low and high temperatures in Murrah buffalo. Journal of Dairy Science 51: $1689-1692$

MASON, I. L. (1974). Environmental Physiology. In the Husbandry and Health of the Domestic. Buffalo pp. 94 95 Rome: Food and Agriculture Organisation of the United Nations.

9. McDOWELL, R. E. (1972). Improvement of Livestock Production in Warm Climates p. 575, San Francisco: W. H. Freeman and Company.

MORAN, J. B. (1973). Heat tolerance of Brahman cross, Buffalo, Banteng and Shorthorn steers during exposure bo sun and as a result of exercise. Australian Journal of Agricultural Research! 24: $775-782$.

11. PAE; R, D. (1952). Effects of summer on temperatures of buffalo calves. Indian Veterinary Journal 29: $210-222$.

12. PANDEY, M. D. \& ROY, A. (1969). Variation in cardiorespiratory rates, rectal temperature, blood haematocrit, and haemoglobin as measures of adaptability in buffaloes to a hot environment. British Veterinary Journal 125 : $463-471$.

13. SCHLEGER, A. V. \& TURNER, H. G. (1965). Sweating rates of cattle in the field and their reaction 10 diurnal and seasonal changes. Australian Journal of Agricultural Research 16: $92-103$

14. STEEL, R. G. D. \& TORRIE, J. H. (1960). Principles and Procedures of Statistics pp. 107 - 109, New York: McGraw - Hill. 